\title{
Convergence Culture: where old and new media collide Henry Jenkins
}

\author{
Resenha - DOI: 10.3395/reciis.v2i1.165pt
}

\section{Sandra Lúcia Rebel Gromes \\ Departamento de Ciência da Informação, Universidade Federal Fluminense, Rio de Janeiro, Brasil sandrarebelgomes@gmail.com}

\section{Ana Rebel Barros}

Universidade Federal Fluminense, Rio de Janeiro, Brasil anarebel@gmail.com

Na seção de "Agradecimentos" do livro Convergence Culture, Henry Jenkins assinala que este culmina após oito anos de uma "jornada épica”, esforço compartilhado com muitos para construir o Programa de Estudos de Mídia Comparativa do MIT, do qual é fundador e diretor. Caracterizando-o como um centro "para conversações sobre mudanças na mídia (passado, presente e futuro)" Jenkins também sublinha seu compromisso com a ampliação do "diálogo público sobre cultura popular e vida contemporânea”. Nessa direção, a obra examina a relação entre sociedade (audiências e produtores midiáticos) e mídias (canais e conteúdos), considerando as recentes (e vertiginosas) mudanças tecnológicas ocorridas neste ambiente de interseção entre velhas e novas mídias, as implicações sociais destas transformações e suas tendências futuras.

O livro é escrito num estilo leve, aliado a um reconhecido rigor acadêmico. Tais qualidades atraem tanto estudiosos quanto outros interessados na temática da cultura da convergência: participantes ativos dos novos ambientes de comunicação e de informação, pioneiros e usuários criativos das mídias emergentes, integrando, conforme Jenkins, "comunidades de fãs”, “educadores envolvidos com comunidades de aprendizado informais", criadores ou consumidores da cultura popular, ativistas, publicitários, executivos e profissionais da indústria de mídia. Seu objetivo é ajudar pessoas comuns a entender

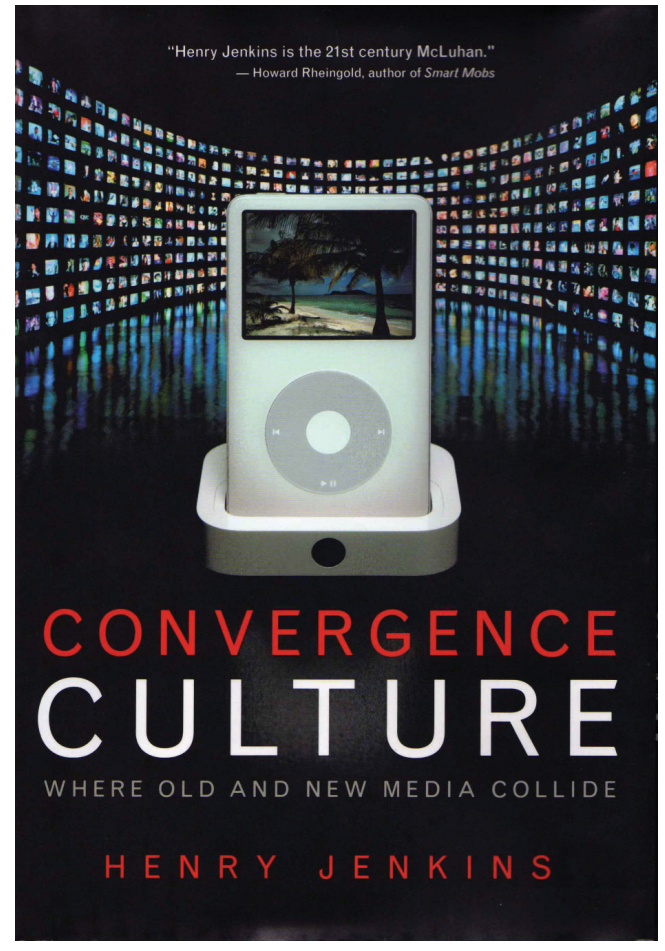

New York, London: New York
University Press, 2006

ISBN: $978-081474281-5$ 
como a convergência tem impacto na mídia que consomem e, ao mesmo tempo, ajudar líderes desta indústria e legisladores a entender a perspectiva do consumidor sobre tais transformações. Um glossário ao final relaciona termos centrais, vários deles com múltiplos significados conforme os diferentes contextos tratados ao longo do livro.

Premiado em 2007 pela Society for Cinema and Media Studies Katherine Singer Kovacs Book Award, Convergence Culture é um dos livros mais recentes escritos por Jenkins, juntamente com The Wow Climax: Tracing the Emotional Impact of Popular Culture (2007), Fans, Bloggers, and Gamers: Exploring Participatory Culture (2006), todos focalizando variados aspectos da mídia e cultura popular, nenhum deles publicado no Brasil. Jenkins, um conhecido analista de mídia, muito respeitado nos meios acadêmicos, é professor de literatura, mantém um blog de ensaios em www.henryjenkins.org., assina regularmente uma coluna na revista Technology Review, do MIT (http://www.technologyreview.com/index.aspx) e é um dos principais pesquisadores que integram The Education Arcade (http://www.educationarcade.org/), projeto voltado para a promoção do uso educacional dos computadores e dos vídeo-games.

Jenkins se apresenta como um fã bastante ativo das mídias emergentes, sublinha a sua condição de intelectual da área de mídias, sua participação intensa nas discussões "com gente do lado de dentro do mercado e legisladores", bem como menciona a sua atuação como consultor de algumas empresas citadas no livro. Portanto, adverte que não é um observador neutro disto tudo, como deixa claro no capítulo introdutório. Mais um ponto deve ser destacado: ele declara ser otimista em relação ao potencial democrático de algumas das tendências culturais contemporâneas no contexto da cultura convergente, mas pontua que nem todos os pensadores compartilham tal otimismo, citando, por exemplo, Noam Chomsky dentre aqueles que enxergam sobretudo obstáculos decorrentes do poder da "big media" para se alcançar uma sociedade mais democrática.

"Bem-vindo à cultura da convergência, onde as novas mídias enfrentam as velhas mídias, onde as mídias corporativas e alternativas se cruzam, onde o poder do produtor midiático e o poder do consumidor midiático interagem de formas imprevisíveis". Assim Jenkins começa a explicar ao leitor a maneira pela qual caracteriza o fenômeno da convergência. Também recupera, com equidade, o surgimento do conceito como importante elemento de mudança nas indústrias midiáticas. Segundo o autor, quem o focalizou pela primeira vez foi o cientista político do MIT, Ithiel de Sola Pool, no livro Technologies of Freedom (1983), a quem considera "o profeta da convergência das mídias".

O conceito de convergência é definido por Jenkins como o fluxo de conteúdo que atravessa mídias distintas, a cooperação entre diversas indústrias de mídia e o comportamento migratório das audiências. Tal fluxo é fortemente condicionado pela participação ativa dos consumidores, vista pelo autor como crucial para a circulação destes conteúdos. Como sugere o título do livro, para Jenkins o sentido da convergência é, antes de tudo, cultural. Ela não se explica pelo viés da tecnologia, mas pelo reconhecimento de que são cada vez mais difusas as fronteiras que separam criadores/produtores de conteúdos e usuários dos mesmos. Jenkins argumenta: "se colocamos o nosso foco na tecnologia, a batalha será perdida antes mesmo de começarmos a lutar". Parece polêmica a opção que faz de se colocar num ponto de vista tão afastado das tecnologias, já que não se pode ignorar que estas têm um papel importante na disseminação dos conteúdos e implicações fortíssimas nos usos das diferentes mídias que suportam, exigindo ainda diferentes graus de habilidades dos usuários para acesso, fruição, comunicação e interação entre pares. A explicação que oferece liga-se ao relevo que dá à participação em detrimento do acesso. Se o exame deste requereria um foco maior nas tecnologias, aquela direciona a ênfase para o exame de protocolos e práticas culturais.

Para definir a cultura da convergência, Jenkins elege três conceitos-chave - convergência das mídias, cultura participativa e inteligência coletiva. A relação entre os três delineia o instigante e atualíssimo tema abordado no livro, permitindo-nos dimensionar o alcance e o significado deste novo patamar de oferta, produção diversificada e uso das novas mídias. Para compreendermos melhor os seus pontos de vista, deixemos, novamente, que fale o autor:

\begin{abstract}
Argumentarei contra a idéia de que a convergência deva ser entendida primeiramente como um processo tecnológico que leva funções múltiplas para um mesmo equipamento. A convergência representa uma mudança cultural na qual consumidores são encorajados a procurar novas informações e fazer conexões entre conteúdos midiáticos dispersos (p.3).
\end{abstract}

Sobre o conceito de cultura participativa, Jenkins assinala que ele contrasta com as antigas idéias de uma audiência passiva:
Ao invés de falar de produtores e consumidores midiá- ticos em papéis separados, podemos vê-los agora como participantes que interagem uns com os outros de acordo com novas regras, que nenhum de nós compreende por completo. Nem todos os participantes nascem iguais. As grandes empresas - e mesmo indivíduos no âmbito da mídia corporativa - ainda exercem mais poder do que cada consumidor e do que a soma destes. E alguns consumidores possuem mais habilidades do que outros para participar desta cultura emergente (p.3).

O conceito de inteligência coletiva, conforme concebido por Pierre Lévy, é tomado por Jenkins para mais uma vez sublinhar que a convergência acontece antes no cérebro de cada consumidor e através de sua interação social do que através de máquinas e instrumentos, por mais sofisticados que eles sejam:

Como há mais informação sobre todo tipo de assunto
do que alguém poderia guardar na cabeça, há um in-
centivo a mais para conversarmos sobre as mídias que
consumimos. Esta conversa cria o rumor que é cada vez
mais valorizado pela indústria midiática. O consumo
tornou-se um processo coletivo - e é a isso que este livro
se refere como inteligência coletiva (...) Nenhum de nós
sabe tudo; cada um de nós sabe algo; e podemos juntar
as peças se somarmos nossos recursos e combinarmos
nossas habilidades. A inteligência coletiva pode ser en- 
tendida como uma fonte alternativa de poder midiático. Estamos aprendendo a usar este poder nas nossas interações diárias na cultura da convergência. No presente, usamos este poder coletivo principalmente para nosso lazer, mas em breve aplicaremos estas habilidades para propósitos mais "sérios” (p.4).

Os discursos de analistas contemporâneos versando sobre convergência começam e terminam com o que Jenkins denomina "a falácia da caixa preta". Ao contrário do que aqueles acreditam - que todos os conteúdos de mídia irão confluir para uma única caixa preta - Jenkins assegura que tal concepção é redutora. A convergência das mídias, para ele, é mais do que uma mudança tecnológica. "A convergência altera o relacionamento entre as tecnologias existentes, indústrias, mercados, gêneros e audiências (...) e envolve mudanças tanto no modo como as mídias são produzidas quanto na maneira como são consumidas".

Em seis capítulos, o autor apresenta uma colagem de casos que são fenômenos de mídia recentes e muito expressivos para compreendermos como a convergência remodela a relação entre produtores e consumidores. Cada um deles oferece uma contribuição particular para melhor entendimento de tal processo. Dos que se originam da televisão, foram selecionados Survivor (2002) e American Idol (2000); dos que provêm do cinema, The Matrix (1999) e Star Wars (1977); Harry Potter (1998) é um caso proveniente da literatura. Tais exemplos são buscados para ilustrar o que acontece quando pessoas resolvem interagir com outras, participar ativamente ou controlar as mídias que freqüentam.

No primeiro capítulo, Jenkins se concentra na análise do reality show americano Survivor, um programa em que participantes disputam um prêmio de um milhão de dólares em provas de resistência em algum lugar do mundo. Mas o que chama a atenção do autor é a comunidade organizada de fãs (spoilers) que se cria na Internet, com o intuito de investigar em grupo, beneficiando-se das contribuições de cada um, advindas de sua expertise, para descobrir segredos antes mesmo de as temporadas do programa irem ao ar. Mapear como estas comunidades agem, adverte, pode nos ajudar a melhor entender a natureza social do consumo contemporâneo de mídia e a maneira pela qual o conhecimento se torna poder na era da convergência midiática. Para Jenkins, este é um exemplo vividamente particular de inteligência coletiva em ação.

No segundo capítulo, American Idol é analisado da perspectiva da indústria midiática numa tentativa de entender como a reality television está sendo moldada pelo que Jenkins chama "economia afetiva" (affective economics), envolvendo consumidores que são convidados a se engajar emocionalmente e produtores que buscam misturar o conteúdo do entretenimento com a mensagem publicitária.

Os dois casos até aqui abordados, tratam da tensão na relação entre o público e os produtores destas franquias. Jenkins indaga, por um lado, sobre quando a participação pode se tornar interferência e, por outro, sobre quando os produtores podem exercer poder excessivo sobre esta experiência. No caso de Survivor, os produtores temem que a revelação dos resultados para o público em geral, em função da eficiência da comunidade spoiler, esvazie o interesse que o programa possa despertar. No caso de American Idol, são os fãs que passam a temer que o controle dos produtores os alije do processo.

O terceiro capítulo examina a franquia The Matrix como exemplo expressivo do que Jenkins chama "narrativa transmidiática" (transmedia storytelling). Os irmãos Wachowski, que urdiram a história, distribuíram-na não só pelos longas-metragens da trilogia, mas também por curtas de animação, games, sites - de forma que embora só seja possível entender a trama a partir dos filmes, a busca de informações nas outras obras e o movimento dos consumidores via grupos de discussão online pode enriquecer a compreensão da narrativa. Este talvez seja o capítulo mais emblemático das questões que o autor quis expor ao longo do livro. Os leitores certamente descobrirão o porquê.

Os capítulos quarto e quinto nos aprofundam no reino da cultura participativa. O capítulo quatro mostra como os fãs de Star Wars estão remodelando ativamente a saga para satisfazer suas fantasias e desejos. À medida em que esta se expande por várias mídias, é interessante notar que surgem expectativas diferentes por parte dos produtores: enquanto nos games os consumidores são encorajados a gerar a maior parte do conteúdo, nos filmes a participação criadora dos fãs é menor e raramente levada em conta pelos produtores. O capítulo cinco lida com os jovens fãs de Harry Potter que escrevem suas próprias histórias sobre Hogwarts e seus alunos. As políticas de participação, neste caso, envolvem duas questões principais: conflitos de interesse entre os fãs e a Warner Bros. e o conflito entre cristãos conservadores e professores que vêem nos livros um meio de estimular jovens leitores. Nos dois casos, existe conflito com os produtores da mídia comercial que não abrem mão de exercer maior controle sobre a sua propriedade intelectual.

No sexto capítulo Jenkins parece querer deslocar seu foco, ao aplicar suas idéias sobre convergência na abordagem das perspectivas oferecidas pela campanha presidencial americana de 2004, explorando aquilo que, sob sua ótica, deverá ser levado em conta para que a democracia se torne mais participativa. Reitera que os cidadãos foram mais bem servidos, na ocasião, pela cultura popular do que pelas notícias da grande mídia ou pelos discursos políticos oficiais, mediante a veiculação de idéias por iniciativa própria dos cidadãos, estimulados pela campanha, usando diversas mídias. Para ele, as eleições de 2004 representam um importante momento de transição na relação entre mídia e política e, mais uma vez, todos os lados supõem uma participação maior dos cidadãos e consumidores, ainda que não se tenha um acordo sobre o peso desta participação.

$\mathrm{Na}$ Conclusão do livro, Jenkins retoma os três termos-chave que reuniu - convergência, inteligência coletiva e participação - para explorar as implicações da cultura convergente não apenas para o lazer, mas para a educação, reforma da mídia e cidadania democrática. Ele sublinha aqui mais uma vez as idéias de que a cultura convergente representa uma mudança nas formas 
em que pensamos as nossas relações com a mídia, que estamos fazendo esta mudança primeiramente através de nossas relações com a cultura popular, mas que as habilidades que adquirimos podem ter implicações na maneira como aprendemos, trabalhamos, participamos dos processos políticos e nos conectamos com as pessoas ao redor do mundo.

O autor reconhece que o público que está mais profundamente integrado a estes novos comportamentos é ainda bastante restrito: trata-se de homens brancos com ensino superior, em sua maioria. Mas na medida em que o acesso dos cidadãos for ampliado, ele vê as audiências fortalecidas por estas novas tecnologias ocupando mais e mais um lugar na interseção entre as antigas mídias e as emergentes, demandando o direito de maior participação. E assim adverte que os produtores que falharem em negociar com esta nova cultura participativa verão declinar o seu poder: "os compromissos e batalhas resultantes irão definir a cultura pública do futuro".

Ao analisar as implicações culturais, econômicas e políticas da nova relação entre mídia e sociedade, ou seja, as transformações culturais que delas decorrem, Jenkins nos oferece ao mesmo tempo um mapa dos novos territórios onde as velhas e novas mídias se cruzam e um tesouro: os elementos essenciais para percebermos o que pode advir e o nosso possível papel num presente/futuro convergente. 